EstAg 30 (1995) 207-237

\title{
Los sacrificios en la Carta a los Hebreos 10,1-18
}

(Continuación)

\section{INOPERANCIA DE LOS SACRIFICIOS DEL ANTIGUO TESTAMENTO}

\subsection{TEORIAS SOBRE EL ORIGEN DE LOS SACRIFICIOS}

La institución del sacrificio está profundamente enraizada en el AT, aunque no es explicada racionalmente. "La institución es aceptada como una ordenanza divina segura y el único principio está en que la sangre es el símbolo de la vida" ${ }^{119}$. Diversas han sido las teorías sobre los sacrificios, de las cuales haré un resumen de las más significativas ${ }^{120}$ :

a) Las ofrendas o las víctimas serían el alimento de la divinidad. Pero esta hipótesis no es sostenible pues el AT va más allá (Cfr. Num 28,2). Tenemos textos donde podrían inducir a pensar en dicha interpretación (Juc 6,1924; Lv 3,11; Ml 1,7.12), pero si la Biblia menciona esta interpretación popular del sacrificio como alimento para los dioses es para reírse de ella ${ }^{121}$. Tal concepción aparece claramente criticada en el Sal 50,13 y en Dan 14.

b) Otra teoría más difundida fue presentada por Robertson Smith y apoyada por Wellhausen, según la cual la esencia del sacrificio es la comida en comunión con la divinidad ${ }^{122}$. La idea directora de los sacrificios de los animales entre los semitas no era la de un don ofrecido a la divinidad, sino un acto de comunión en el que dios y sus adoradores se unían tomando parte de la carne y la sangre de la víctima sagrada. Según Smith, se pueden diferen123.

119. Abba, R., The Origin and Significance of Hebrew Sacrifice, BulTheoBib 7 (1977) p.

120. Un estudio amplio se puede encontrar en Moraldi, L., Espiazione sacrificiale e riti espiatori nell'ambiente biblico e nell'Antico Testamento, AnBib 5, Roma 1956, p. 3-76.

121. Cfr. Sabourin, L., Op. Cit., 1484.

122. Smith, W.R., Lectures on the Religion of the Semites, London 1894, p. 226-227. Tomado de Abba, R., Op. Cit., p. 123. 
ciar 3 etapas que corresponden cada una de ellas a un tipo de sacrificio: El sacrificio de comunión, donde el dios come con su pueblo; el sacrificio expiatorio, donde el animal muere para expiar al hombre culpable; y el sacrificio místico, en el que dios mismo es sacrificado y comido por los adoradores.

Esta teoría no ha carecido de críticas ${ }^{123}$, por lo que Sabourin concluye que "la historia de la evolución del sacrificio -de la comunión a la expiacióndesarrollado por J.Wellhausen y W.R.Smith no corresponde al conjunto de los textos" 124 .

c) Otros autores como Taylor y Gray consideran el sacrificio como un don. Para ello se apoyan en la terminología usada, como son los conceptos

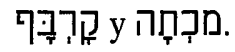

Pero hoy, la mayoría de los estudiosos coinciden que no es posible atribuir a una sola teoría todos los textos sacrificiales del AT y las teorías presentadas no se excluirían entre sí sino que se complementarían. Por tanto, el sacrificio es un concepto complicado que no se puede explicar con teorías simplistas ${ }^{125}$. Otros autores distinguen entre ofrendas y sacrificios, siendo la inmolación la diferencia específica que hace de la ofrenda un sacrificio.

El sacrificio es, mediante un acto solemne humano, la expresión de la idea que todo pertenece a Dios y el reconocimiento de este derecho, al mismo tiempo que es una indicación del deseo humano de acercarse a la divinidad.

\subsection{CRITICA DE LOS SACRIFICIOS EN EL ANTIGUO TESTAMENTO}

El tema de la crítica profética en relación con el culto, y por tanto en relación con los sacrificios, es complejo y en la historia de la exégesis se han dado multitud de opiniones. Desde quienes afirman que hay un rechazo total por parte de los profetas, pasando por los exégetas moderados hasta llegar a afirmar que los profetas apoyaban el culto. Todo depende de la perspectiva

123. Así para R.J.Thompson, la teoría de Smith no es verificable en la Biblia, ya que en el relato Yahwista, los sacrificios patriarcales son ritos que inspiran un terror respetuoso y no alegría. También los sacrificios descritos por el Elohista pertenecen a la categoría de ritos donde la motivación solemne es asociada a la purificación de los pecados. Lo mismo sucede en otros libros del AT. Sólo algún texto apoya la teoría de Smith.

124. Sabourin, L., Op. Cit., 1487.

125. Según R. de Vaux: "El sacrificio es un acto con muchos aspectos y nos debemos abstener de teorías simples. El sacrificio no es meramente un don, ni tampoco significa una unión con Dios, ni siquiera un medio para expiar el pecado: hay varios motivos que aplicados al mismo tiempo satisfacen algunos instintos imperativos de la consciencia religiosa". Tomado de Abba, R., Op. Cit., p. 124s. 
que se tome, pues se encuentran textos para apoyar distinta posturas. La cuestión se puede definir como caleidoscópica. Un estudio amplio acerca de las posturas nos la muestra L. Ramlot ${ }^{126}$. A pesar de ser difícil hacer un balance de las posiciones, frecuentemente contradictorias y enmarañadas en múltiples problemáticas, este autor llega a unas conclusiones que me parecen importantes:

“a) La crítica del culto por parte de los profetas concerniría sea las contaminaciones cananeas, sea la hipocresía de los adoradores o sacerdotes, para quienes el culto era una coartada para la inmoralidad o para la injusticia social.

b) Es reconocido el carácter profético de algunos salmos, e inversamente, aparecen manifiestas afinidades litúrgicas en los profetas.

c) La noción de culto es totalizante... Es la expresión de un reencuentro con Dios, donde se recuerda que Dios tiene la iniciativa de la salvación, pero que supone realizadas todas las condiciones de la alianza y así de la ética política, social y personal.

d) ...Retenemos como razonable una vocación de Isaías en el Templo de Jerusalén...es decir, consideramos la presencia y la predicación de los profetas en el Templo y su misma predicación en el trascurso de las liturgias. Pero no habría el status de 'un profeta cultual' comparable a éste del rey" ${ }^{127 .}$

126. Ramlot, L., Prophètisme. La Bible, DBSup VIII, 909-1222, pero especialmente 11211166. Por una parte estarían quienes afirman un rechazo total del culto por parte de los profetas, para lo cual se apoyan en textos que aíslan del contexto. Destacan los textos: Am 4,4; 5,21ss; Os 6,6; Is 1,10ss; 29,13; Miq 6,6-8; Jer 6,20; 7. Los iniciadores de esta corriente fueron Wellhausen y Volz. Los profetas contraponen culto y Dios. Es un culto profundamente ateo, por lo que Dios no tiene otro remedio que abolirlo. Según Hertzberg, era insanable la discrepancia existente entre la acción litúrgica cumplida con las manos y los labios y una vida vacía de contenidos éticos.

Otros autores como H. Gunkel y S. Mowinckel apoyan una revalorización cultual. Así subrayan la importancia de la presencia de ciertos profetas junto a los sacerdotes en los santuarios y que habría incluso profetas deil Templo como Joel y Abacuc.

Engnell distingue un doble profetismo: uno de inspiración y otro de institución. Para él, las críticas al culto hechas por los profetas se no tratarían más que de una polémica contra las distintas desviaciones. Admite como profetas cultuales a Joel, Nahum, Abacuc, Ageo, Zacarías, incluso los grandes profetas estaban ellos mismos en relación positiva con los lugares cultuales. Para S. Kapelrud, los profetas se habrían levantado contra los orígenes no yahwistas del culto y afirma que el trasfondo de los profetas habría que buscarlo en el culto. También Adam Welch ve en los profetas la crítica al culto popular que estaba inspirado en prácticas cananeas, lo que es muy distinto de una condenación del culto en sí.

Una postura más radical la tenemos en Hentsche para quien los profetas han condenado rigurosamente el culto que tenían ante sus ojos, amenazado de cananeización y de formulismo hipócrita o casi mágico. Si hay que abstenerse de una generalización, los profetas manifiestan, en su conjunto, muy poca estima por el culto y la crítica dirigida contra el culto iría mucho más allá de los abusos existentes, criticando el culto como medio de unirse a Dios y proponiendo una religión interior de fe.

127. Ramlot, L, Op. Cit., 1145-1146. 
Hay que mirar con reservas la tesis que afirma la existencia en Israel de un movimiento importante de profetismo cultual ${ }^{128}$. Pero para ver la actitud de los profetas, nada mejor que ver los rasgos fundamentales de varios de ellos en relación al culto.

Amós no condenaría el culto sino sus desviaciones. Los sacerdotes no son criticados porque son sacerdotes, sino porque no lo son como deben serlo. Pero ante lo dicho, ¿Amós 5,25 no afirmaría lo contrario? ¿Condenaría Amós toda la liturgia sacrificial? Este versículo se debe colocar en el conjunto del libro donde Amós no se opone más que a los sacrificios mal celebrados. Según Monloubou, "Amós no expresa ni una afirmación histórica ni un juicio de valor sobre los sacrificios, sino que en su deseo de purificar la liturgia corrompida, él se toma la libertad de elegir una fórmula que será tanto más eficaz cuanto más absoluta sea ella" ${ }^{129}$. De Vaux al estudiar este texto junto con Jer 7,21, hace hincapié en la gramática hebrea y en las formas de negación usadas en dicha gramática, lo que él llamará la "negación dialéctica" ${ }^{130}$. Afirma: "Crean unos dichos sapienciales, los cuales no eran dirigidos contra el culto en sí, sino contra el culto material y exterior que era practicado por sus contemporáneos" ${ }^{131}$.

Pero el texto más citado respecto a la crítica profética del culto es Jer 7,21 ss donde a simple vista tenemos una condena de los sacrificios y una valorización de la ética. "Acerca de los sacrificios, Dios no había ordenado nada..." Esta expresión parece una bofetada al código Sacerdotal que describe todos los detalles de los sacrificios.

Weinfeld ha explicado este texto de la siguiente manera: "La intención de Jeremías es que los 10 mandamientos, considerados como si fueran la primera constitución de Israel, no decían nada acerca de los sacrificios" ${ }^{132}$.

128. Un representante de esta teoría es Gonzáles, A., Profetismo y sacerdocio. Profetas, sacerdotes y reyes en el antiguo Israel, Madrid 1969. Este autor nos presenta las distintas posturas de exégetas al respecto. Esta teoría intenta hacer del profeta un funcionario litúrgico, cuya misión sería la de pronunciar los oráculos en nombre de Yahwé.

Según Alonso Schöckel, A.,- Sicre Díaz, J.L., I Profeti, Roma 1989, p. 46: "La teoría del profetismo cultual tiene razón cuando considera al profeta incorporado a la vida religiosa de su tiempo; cuando investiga el influjo del culto sobre sus géneros del lenguaje profético. Pero tiene sus puntos débiles: el uso general del término 'profeta', la identificación de las funciones del profeta y del sacerdote, la elevación a categoría probante de todo contacto de un profeta con el santuario". Concluye diciendo que "El profetismo cultual es una hipótesis de trabajo: clarifica algunos puntos y oscurece otros".

129. Monloubou, L., Prophètes. Amos, DBSup VIII, 723.

130. Vaux, R. de, Das Alte Testament und seine Lebensordnungen, II, Freiburg 1962, p. 306. Un estudio sobre la negación dialéctica la encontramos en Kruse, H., Die dialektische Negation als semitisches Idiom, VT 4 (1954) p. 385-400.

131. Vaux, R. de, Op. Cit., II, p. 275.

132. Weinfeld, M., Jeremiah and the Spiritual Metamorphosis of Israel, $Z A W 88$ (1976) p. 53. 
Jeremías implica en este texto que la alianza original no incluía tal mandamiento de sacrificar. Esta parece que es una interpretación muy benevola del texto de Jeremías.

Por su parte, Milgron hace una interpretación personalista o de ámbito individual, lo cual no aparece en el texto: "Jeremías no tiene nada que decir acerca de los sacrificios fijos del templo, tales como el tamîd. Mas bien se dirige a la gente y les instiga a renunciar a sus sacrificios individuales porque su piedad ritual está viciada por su comportamiento inmoral" ${ }^{133}$. Para hacer

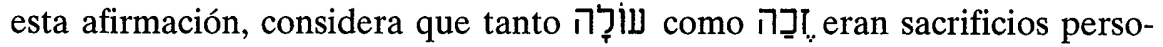
nales e individuales, lo cual no es cierto. De Vaux expresa el mismo juicio que para el texto de Amós visto anteriormente.

Tenemos otros textos de Jer 17,26; 33,18; 30,17-24 donde hay una aceptación de los sacrificios. Pero los exégetas concuerdan en afirmar que estos textos no son del propio Jeremías.

El tema del sacrificio también lo encontramos en los profetas exílicos y post-exílicos (hay que tener presente la reformáa cultual de Josías). El Dt-Is nos presenta dos textos sobre los sacrificios. En el primero, Is 40,16, no hay un rechazo de los holocaustos sino que el autor reconoce los límites que comporta el mejor de los sacrificios, pero no los rechaza de antemano. "Se puede ver allí mismo un dar coraje, aunque siempre bajo la reserva que las condiciones de un culto auténtico sean cumplidas" ${ }^{134}$. El segundo texto, Is 43,22-24, se encuentra en la línea de los profetas promotores de una religión espiritual. "El no rechaza el culto más que Jeremías o Amós lo hayan rechazado, sino que él pide la espiritualización" ${ }^{135}$. Se puede afirmar por tanto, que el Dt-Is no es muy crítico con los sacrificios y que éstos no eran un tema que le preocupara en exceso.

El Trito-Is nos habla de la glorificación de Dios por medio de los sacrificios (Cfr. Is 56,$7 ; 60,7$ ), pero no pierde de vista las exigencias de la pureza y de la lealtad. Protesta contra quienes piensan en una eficacia mágica de los sacrificios o el mezclar prácticas ortodoxas y paganas (Is 63,$3 ; 66,3)$ o quien confía en el templo (Is 66,1-2).

En Ezequiel, como sacerdote y profeta, encontramos los sacrificios clási-

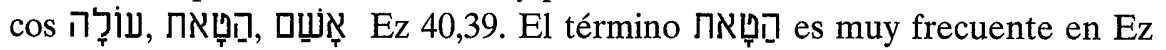
$(42,19.21 ; 43,22.25 \ldots)$, y esta insistencia prepara la legislación del códice Sacerdotal sobre los sacrificios expiatorios. "Ezequiel se distingue por su

133 Milgron, J., Concerning Jeremiah's Repudiation of Sacrifice, $Z A W 89$ (1977) p. 274.

134. Chary, Th., Les prophètes et le culte à partir de l'exil, autour du second Temple. L'idéal cultuel des Prophètes exiliens et post exiliens, Tournai 1955, p. 87.

135. Chary, Th., Op. Cit., p. 89. 
conocimiento del templo y por su preocupación por el culto, así como también por su atención a las reglas de la pureza legal $(4,4)$ y a las faltas contra el culto" 136 .

En Zacarías, "aunque el profeta esté ocupado continuamente con el templo y con el culto, pero él no nos muestra casi nada de las actividades cultuales propiamente dichas" ${ }^{137}$. Sólo el ayuno es la práctica que nos describe, pero la práctica externa debe ser unida a una vida religiosa interior auténtica (Zac 7,8-14).

Para Malaquías hay una incompatibilidad total entre el pecado y el culto y prefiere la abstención total del culto a una apariencia falsa de un culto puramente formalista (Mal 1,10).

La brevedad de Ageo no nos permiten aclarar su actitud cultual. En cuanto a Joel, sólo nos menciona dos elementos estrictamente sacrificiales

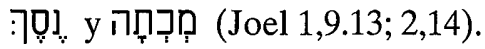

De toda esta presentación de los profetas se puede concluir que sus críticas antisacrificiales habrían sido dirigidas sobre todo contra las ofrendas o inmolaciones puramente maquinales y ponen el acento en el espíritu que debe acompañar a estas ofrendas. Cuando rechazaban en nombre de Dios los sacrificios rituales, se guardaban mucho de atacar la ley. Por tanto no se pueden tomar al pie de la letra sus declaraciones sobre la exclusión de los sacrificios, ya que la ley exigía formalmente ese género de sacrificios. Con razón concluye A.Vanhoye, "que lo que criticaban ante todo no eran los propios ritos, sino la falta de las disposiciones requeridas en los que participan de ellos. Por tanto, la actitud justa parecía ser la de seguir ofreciendo los sacrificios rituales, pero esforzándose en tener unas disposiciones interiores dignas de Dios" ${ }^{138}$. La palabra profética es el remedio a todo ritualismo mágico y actualizan las exigencias sociales y personales de la alianza divina, y se oponen a la monótona repetición de liturgias estereotipadas. Sería impensable para los profetas el sacrificio con efecto opere operato. Estas actitudes proféticas influyen decisivamente en el NT.

\subsection{CRITICA A LOS SACRIFICIOS EN EL NUEVO TESTAMENTO}

El NT dice sorprendentemente poco acerca de los sacrificios porque el cristianismo se desarrolló más en la línea nomista del pensamiento religioso

136. Auvray, P., Prophètes. Ézéquiel, DBSup VIII, 780.

137. Chary, Th., Op. Cit., p. 143.

138. Vanhoye, A., Sacerdotes antiguos, sacerdote nuevo según el nuevo testamento, Salamanca 1984, p. 226. 
judío (especialmente la tradición farisea) que en la línea cúltica (representada por los sacerdotes y los saduceos). Una excepción a esto lo constituyen el Apocalipsis (centrado en el culto de la Nueva Jerusalén) y Heb que intenta explicar cómo la Nueva Alianza completa y sobrepasa el culto sacrificial del AT.

Una lectura de los evangelios nos permite constatar que Jesús nunca repudió formalmente el sacrificio, pero adoptó una actitud profética, según la cual la moralidad era mucho más importante y actuó consecuentemente.

De la enseñanza y actividad de Jesús se puede ver que algunos textos implican una actitud favorable hacia los sacrificios. Entre estos textos se pueden citar: Mt 5,23-24; Mc 1,44; 12-41-44. Su dura crítica al abuso del "kop $\beta \tilde{\alpha} \nu$ " (Mc 7,9-13 par) tiene sentido sólo en el contexto de una actitud positiva hacia el sacrificio.

Otros textos, por su parte, expresan una crítica sobre los sacrificios o el templo (Mc 11,15-19) donde Jesús ve el templo como casa de oración y no para ofrecer sacrificios (Mc 14,58) o sobre el sábado (Mt 12,1-8). También la parábola del Buen Samaritano implica una crítica mordaz contra la institución sacerdotal (Lc 10,29-37).

Resumiendo, se puede decir que "algunos dichos de Jesús indican la aprobación, pero los autores sinópticos generalmente presentan a Jesús como un crítico en relación al sistema sacrificial. Su venida ha sustituido el culto del AT con un servicio litúrgico de amor. Este tema, lejos de ser una nueva invención cristiana, estaba ya incipientemente presente en el pensamiento religioso judío del tiempo del NT" 139 .

La idea del sacrificio de Cristo es central en el NT. Así la forma en que Pablo habla de la Eucaristía en 1 Cor 10 y 11 tiene sentido sólo cuando se concibe la cena y pasión de Jesús como sucesos sacrificiales (Mc 14,12-17 par). La institución de "hacer esto en memoria mía" (Lc 22,19; 1 Cor 11,2425) parece hacer alusión al recuerdo de la Pascua. "Mi sangre de la nueva Alianza" (Mc 14,24; Mt 26,28) se refiere a Ex 24,3-8, al sacrificio de la Alianza. "Derramada por muchos para el perdón de los pecados" (Mt 26,28) indica el significado de la expiación. De este modo, las palabras de la institución muestran claramente la muerte de Jesús como cruenta, sacrificial y expiatoria. En los Hechos de la Apóstoles, el carácter sacrificial y expiatorio de la muerte de Jesús no parece ser particularmente enfatizado por Lucas. Pero aquí recibe especial atención el templo, que como en los sinópticos, es tratado positiva y negativamente. Así los cristianos rezan en el templo $(2,46 ; 3,1$ - 
$4 ; 21,26 ; 22,17)$. La crítica al mismo la encontramos en el episodio de Esteban (cap 6 y 7 ).

\subsubsection{Teología paulina del sacrificio ${ }^{140}$}

Su teología sacrificial se puede dividir en tres puntos:

a) El sacrificio de Cristo

Los textos que contienen esta teología de autoentrega por nosotros son 2 Cor 5,14-15; Rom 5,6-11; 8,23; Gal 2,20; Ef 5,2.25; Col 1,24; 1 Tim 2,5-6; Tit 2,13-14. En 1 Cor 5,7 leemos: "Cristo nuestro cordero pascual ha sido sacrificado" lo que hace suponer que Pablo considera la muerte de Jesús dentro del contexto de la Pascua judía. La idea de Cristo como ofrenda por los pecados la encontramos en 2 Cor 5,21 ${ }^{141}$ y Gal 3,13. "La muerte redentora de Cristo ha sido vista por Pablo como cumplimiento tanto del sacrificio pascual como del sacrificio por los pecados" ${ }^{142}$. Así Pablo se coloca en el contexto de la tradición judía relacionando la muerte de Jesús con las fiestas religiosas judías de la Pascua y del Yom Kippur.

b) Los cristianos como nuevos templos

La idea del cristiano como nuevo templo nos la presenta Pablo en 1 Cor 3,5-17 (Cfr. 1 Cor 6,15.19; 2 Cor 6,16) donde nos describe la comunidad cristiana como planta, como edificio en construcción y, finalmente, la llama templo de Dios o del Espíritu. Pero será en Ef 2,19-22 donde encontramos la imagen de la construcción-edificio ampliamente desarrollada. La figura de la comunidad como templo es descrita como un proceso interno de crecimiento hacia la santidad para ser verdaderos templos. En Ef 4,11-16 usa la metáfora del cuerpo.

c) El sacrificio de los cristianos

Pablo y otros textos del NT comparan, explícita o implícatamente, la vida del cristiano con la muerte sacrificial de Cristo. Son los textos denomi-

140. Cfr. Daly, R.J., Op. Cit., p. 59-67 y en The New Testament Concept of Christian Sacrifical activity, BulTheoBib 8 (1978) p. 100-105.

141. Cfr. Sabourin, L., Rédemption sacrificielle: Une Enquête Exégética, Studia 11, Montreal 1961. Ver también "Christ made 'sin' (2 Cor 5,11); Sacrifice and Redemption in the History of the Formula", en Lyonnet, S.-Sabourin, L., Sin, Redemption and Sacrifice; a Biblical and Patristic Study, AnBib 48, Rome 1970, p. 187-296.

142. Daly, R.J., Op. Cit., p. 100. 
nados "liturgia de la vida", tales como Rom 12,1-2; 15,15-16 ${ }^{143}$; Fil 2,17-18; 1 Pe 2,4-10; Heb 10,19-25; Heb 12,18-13,16.

Una fuerte crítica a los sacrificios rituales nos la presenta Pablo en 1 Cor 10,19-21, donde califica los sacrificios del antiguo Israel como idólatras y por tanto no dirigidos a Dios. Por eso el cristiano no puede seguir participando "de la mesa del Señor y de la mesa de los demonios", lo cual nos indican que había cristianos que participan en ambos sacrificios.

Uno de los textos más ricos para la teología del sacrificio en el NT lo tenemos en $1 \mathrm{Pe} 2,4-10$. Este texto desarrolla el tema del templo paulino, así como el concepto de sacrificio de los cristianos. "Teológicamente, la nueva imagen de piedras vivas no sólö enfatiza la importancia de las disposiciones internas, sino que refuerza el mensaje central de Rom 12: el verdadero sacrificio cristiano signifíça ponerse uno mismo totalmente, cuerpo y alma, a disposición de Dios y del vecino" ${ }^{144}$. En este pasaje destaca la forma cristiana de culto espiritual y la mediación de Cristo dentro de una teología de la aceptación.

Pero será sin lugar a dudas en Heb donde tengamos infinidad de textos sobre el sacrificio de Cristo contrapuesto a los sacrificios del AT.

\subsection{LOS SACRIFICIOS EN HEBREOS}

El autor de $\mathrm{Heb}$, poniendo en tela de juicio que la sangre de animales no es un sacrificio adecuado, estaba aceptando una idea que era ampliamente aceptada en el mundo helenista. Ya hemos visto que incluso dentro de la tradición judía, en los salmos y en los profetas, había una corriente que condenaba la creencia en la eficacia automática de los sacrificios, pidiendo en su lugar un sacrificio de acción de gracias y obras de misericordia (Cfr. Am 5,21-24; Miq 6,6-8; Is 1,10-17; Sal 50,7-15).

En Qumran ${ }^{145}$, la creencia en la contaminación del templo, les llevó a renunciar a tomar parte del culto y a reinterpretar el lenguaje sacrificial, de modo que los sacrificios apropiados incluían la oración y la alabanza.

143. En Rom 15,15-16, Pablo concibe su misión apostólica como un servicio sacrificial de anuncio del evangelio de Dios para que las ofrendas de los gentiles puedan ser aceptadas.

144. Daly, R.J., Op. Cit., p. 66.

145. Fiorenza, E.Sch., Cultic language in Qumran and in the New Testament, $C B Q 38$ (1976) p. 165: "La secta de Qumrán no rechazó las instituciones cúlticas porque cuestionaran fundamentalmente la validez del culto de Jerusalén, sino porque esta secta tenía la pureza y la santidad cúltica de Israel en gran estima". Bibliografía sobre este tema, cfr. Baungarten, J.M., Sacrifice and Worship among the Jewish Sectarians of the Dead Sea (Qumran) Scrolls, HTR 46 (1953) p. 141-159; Hengel, M., Judentum, p. 407-414; Haag, H., Das liturgische Leben der Qumrangemeinde, ArLtgW 10 (1967) p. 83-85. 
Después de la destrucción del templo en el año $70^{146}$, los judíos volverán a la tradición profética para justificar el reemplazo del viejo culto por los actos de misericordia. El ilumismo helenista había extendido la creencia que un verdadero sacrificio no necesitaba ni sangre de animales ni un templo físico $^{147}$.

La tendencia hacia la "espiritualización" o reinterpretación del concepto de sacrificio es el trasfondo para analizar el marco intelectual del autor de Heb.

La actitud de Heb con relación a los sacrificios ha sido vista de distintas maneras. Para Loewenich ${ }^{148}$ el concepto de sacrificio en Heb es un desarrollo de la crítica profética del culto. Otto Michel ${ }^{149}$ ha negado cualquier tipo de relación entre Heb y la filosofía helenista $:$ n el tema sacrificial.

La discusión sobre el tema de los sacrificios lo encontramos en Heb 9-10, donde aparece en un contexto cúltico (Cfr. sección 7,1-10,18). A pesar de haber usado ya términos cúlticos en 2,$17 ; 4,14-16 ; 5,1-10 ; 6,19-20$, será en nuestra sección donde discuta el culto detalladamente. Su método, se puede decir que es la comparación para mostrar a sus oyentes que el sacrificio de Cristo es superior y eficaz frente a la ineficacia de los sacrificios de la ley. Esta confrontación está expresada filológicamente con la adversativa $\mu$ È.... ¿é $(9,1.11)$, donde se comparan a Moisés y la ley $(9,19.22)$, el sumo sacerdote $(9,25)$ y Cristo $(9,24.28)$. En nuestra sección el autor contrapone la ineficacia de los sacrificios antiguos (10,1-10) a la eficacia del sacrificio de Cristo (10,11-18).

Heb 9 es el centro teológico de la doctrina de nuestro autor referente a los sacrificios ${ }^{150}$. Su valoración negativa de los sacrificios de la antigua alianza la tenemos en tres textos fundamentales: 9,1-10; 10,1-4; 10,11.

La alianza del Sinaí poseía aparentemente todo lo que necesitaba para funcionar: un "santuario" que, en principio constituía un lugar de encuentro

146. Guttmann, A., The End of the Jewish Sacrificial cult, HUCA 38 (1967) p. 148, nos da tres razones de la desaparición de los sacrificios públicos: "La destrucción del Templo fue sólo una de las causas que determinaron el fin del culto sacrificial. Una segunda fue la reluctancia de los líderes rabínicos de reavivar el poder de la casta sacerdotal. Una tercera fue el cambio de la política romana pues el proponer ellos al sumo sacerdote no había sido eficaz, por lo que no propusieron ni aceptaron ningún otro sumo sacerdote".

147. Cfr. Young, F., Temple, Cult and Law in Early Christianity, NTS 19 (1973) p. 325-338.

148. Loewenich, W. von, Zum Verständnis des Opfergedankens im Hebräerbrief, $T B L 12$ (1933) p. 167-172.

149. Michel, O., Der Brief an die Hebräer, KEK 13, Göttingen 19666, p. 328.

150. Un estudio detallado del capítulo 9 lo encontramos en Thompson, J.W., Hebrews 9 and Hellenistic concepts of Sacrifice, $J B L 98$ (1979), p. 567-578. 
con Dios, y unos "ritos" que debían permitir al sacerdote entrar en contacto con Dios.

El autor recuerda brevemente cómo estaba organizado el lugar santo (Heb 9,2-5) para pasar posteriormente a las reglamentaciones de las ceremonias que allí se realizaban (Heb 9,6-7). La entrada del Sumo Sacerdote en el santo de los santos constituía la cumbre hacia la que tendía todo el culto del AT. El énfasis de 9,1-10 está en mostrar los defectos del culto levítico como

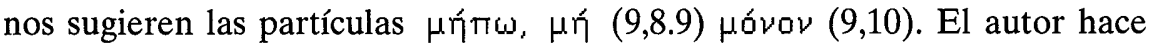
una crítica metódica y mordaz, una constatación de impotencia y de fracaso: "Todo ello es una figura del tiempo presente, en cuanto que allí se ofrecen dones y sacrificios incapaces de perfeccionar en su conciencia al adorador, y sólo son prescripciones carnales, que versan sobre comidas y bebidas y sobre abluciones de todo género, impuestas hasta el tiempo de la renovación" (Heb 9,9-10).

En esta frase se indica una imposibilidad, el medio empleado ("dones y sacrificios"), así como el objetivo que tendrían que alcanzar: una transformación profunda de la persona mediante el perfeccionamiento de su conciencia. El resultado del sacrificio debe ser ante todo transformar a quien lo ofrece, hacer al hombre digno de presentarse ante Dios. La crítica que hace Heb a los sacrificios antiguos se puede concretar en la palabra ineficacia, dado que no alcanzan su objetivo de transformar al hombre. Esto se debe al carácter externo y material que tienen dichos sacrificios, así como a las víctimas y a los sacerdotes que los ofrecen. Una demostración de dicha impotencia es la continua repetición de los mismos. Estos sacrificos en vez de alcanzar su finalidad, lo que hacen es crear en el hombre una conciencia de angustia, por lo que nuestro autor llega a la conclusión que dichos sacrificios deben ser suprimidos por el nuevo sacrificio de Jesús. Ahora desarrollaré estas ideas.

La institución cúltica antigua centraba sus esfuerzos en conseguir lo que se expresa con el término: $\tau \in \lambda \in$ íw $\iota 5$, que conllevaba el perdón de los pecados. Uno de los aspectos más significativos para la comprensión de la crítica de Heb sobre el culto es la purificación de los pecados. El autor repite que el antiguo culto no la podía conseguir $(10,4 ; 10,10)$ e incluso que la iteración de los sacrificios tenía un efecto contraproducente (10,2-3); en cambio, no deja de acentuar que el Nuevo Sacerdote consigue la remisión de nuestro pecado. Siguiendo la corriente del AT, el autor sabe que esta perfección, entendida como remisión de los pecados, no puede conseguirse sino en el culto y, concretamente, en el sacrificio.

Como dice Heb 9,9-10, éstos no pueden dar la perfección, dando a la vez la razón de esta impotencia: el hombre precisa de una "perfección de conciencia" mientras que los sacrificios eran "observancias de carne" que no 
podían pasar más allá de una cierta pureza de la carne ${ }^{151}(9,13)$ o una purificación cultual, es decir, exterior e independiente de la condición interior del oferente. Pero es en la conciencia del hombre donde radica su pecado y es ella quien debe ser purificada y llevada a la perfección o transformada ${ }^{152}$, cosa que no se puede hacer con sacrificios externos. Los defectos de este culto se deben a que son materiales, es decir se trata de disposiciones materiales $(9,10 \mathrm{~b})$ que se refieren a las bebidas, alimentos y las distintas purificaciones $(9,10 \mathrm{c})$ a las que el autor reconoce sólo la función de otorgar una purificación cultual. "Porque se trata de disposiciones materiales, su eficacia es material y no puede alcanzar la interioridad de la conciencia y purificarla de los pecados" ${ }^{153}$. Esta materialidad la tenemos expresada en los términos

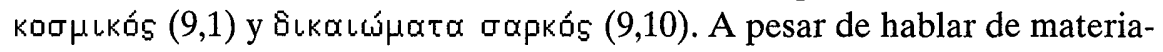
lidad, no creo que el juicio del autor dependa de un dualismo metafísico que oponga el mundo material al mundo espiritual, sino que derivaría directamente de la consideración de la experiencia del AT.

Frente a esta materialidad opone $(\delta \hat{e}$ 9,11) el sacrificio y santuario de Cristo (9,11-14). Aquí encontramos un suceso $\varepsilon$ i $\sigma \bar{\eta} \lambda \hat{\theta} \in \nu(9,12)$ y el significa-

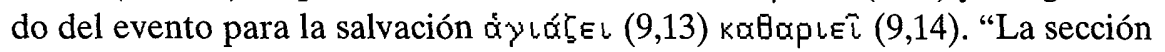
$9,11-14$, como un contraste con 9,1-10, intenta contrastar el nuevo evento y sus efectos con esos que ocurrían en el culto levítico. El suceso, como 9,11-12

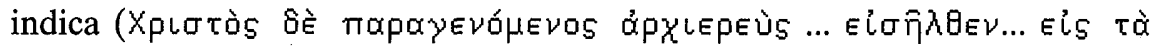
ăyıa) es la exaltación de Cristo" 154 .

Este evento es descrito con un balance quiástico de afirmaciones positivas y negativas en 9,11-12:

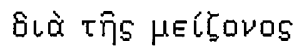

$$
\begin{aligned}
& \text { ou XeLPoTOLர́tou }
\end{aligned}
$$

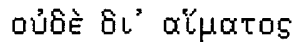

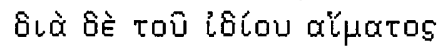

151. Según Mora, G., Ley y sacrificio en la carta a los Hebreos, RCatalT 1 (1976) p. 9: "La razón última del juicio de Heb sobre los sacrificios antiguos y, por ello, sobre todo su mundo,

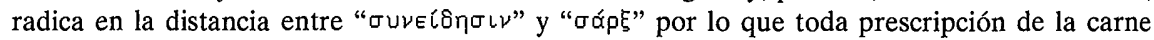
nunca puede alcanzar la conciencia del hombre, su realidad específicamente humana".

152. Vanhoye, A., Sacerdotes antiguos, sacerdote nuevo según el nuevo Testamento, p. 196: "En ese plano el culto antiguo no disponía de ninguna mediación eficaz. La víctima ofrecida sufría ciertamente una transformación, pero en el sentido de una destrucción. En cuanto al que la ofrecía, permanecía forzosamente fuera del sacrificio...Por consiguiente, no había más remedio que reconocer la impotencia del culto, su ineficacia radical".

153. Casalini, N., I sacrifici dell'antica alleanza nel piano salvifico di Dio secondo la lettera agli Ebrei, RivB 35 (1987) p. 447.

154. Thompson, J.W., Op. Cit., p. 569. 
La superioridad de la ofrenda de Cristo está en la naturaleza de su santuario y de su sacrificio; las dos frases negativas indican que la obra de Cristo no tiene los defectos del culto levítico mientras que las frases positivas describen la trascendencia de Cristo.

La impotencia de los sacrificios antiguos no se debe a una simple "falta de poder purificador", como si su diferencia con el de Cristo fuera sólo de grado; su ineficacia se jugaba en su misma esencia y naturaleza. Precisamente, en la medida que eran ofrendas más allá del que hacía el culto, eran por definición inútiles. Semejantes ritos simbolizaban una transformación, pero sin poder alguno para llevarla a cabo. Todo se quedaba a nivel superficial.

La purificación del pecado conlleva la liberación de su angustiosa conciencia; por ello, el hecho de repetir los sacrificios por el pecado ilimitadamente, demuestra que éste no ha sido todavía purificado y en ello está implícito su fracaso e inoperancia, pues quiere decir que no alcanzan su objetivo. Es más, en esta repetición de los sacrificios hay un "recuerdo de los pecados cada año" $(10,3)$.

Por las razones aducidas, Mora concluye que "una institución que intenta la purificación del pecado no sólo es impotente para ello, sino que, precisamente por esta causa y en los mismos ritos que utiliza, produce el recuerdo, la reactivación y el afincamiento del mismo pecado. La antigua institución por ser ineficaz era contraproducente... pues conseguía la renovación del pecado (10,1-4)" 155 .

En Heb 9,8 nos induce a pensar que, según el autor, la ineficacia salvífica de los sacrificios del AT tiene una razón teológica: Dios no había revelado todavía el camino del santuario, es decir, el modo para acceder a El.

Unido a lo dicho sobre los sacrificios en sí mismos, hay que añadir que la ley establece como sumos sacerdotes a hombres afectados por la debilidad. Heb no reflexiona sólo sobre las ofrendas de los sacerdotes o sobre sus funciones, sino sobre las "personas" de los sacerdotes en sí mismas. Así subraya que ellos eran "personalmente" pecadores y que precisaban de sacrificios por sus propios pecados, ofreciendo sólo después por los del pueblo.

La misma impotencia referida a los sacrificios en general, la encontramos referida a la sangre. En Heb 9,12 encontramos el contraste entre

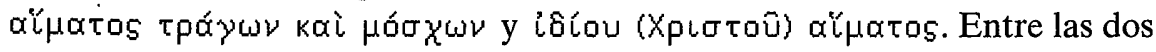
ofrendas hay una distinción cualitativa. Es un texto similar a 10,4 donde los califica con á8uvarov ${ }^{156}$,"es imposible que la sangre de toros y machos

155. Mora, G., Op. Cit., p. 12.

156. La palabra ớ์úva tov distingue Heb de la petición profética de unir sacrificio y misericordia. Aquí es una abrogación total de la multitud de sacrificios. 
cabríos borre pecados", lo cual indica la impotencia de los ritos cultuales, de

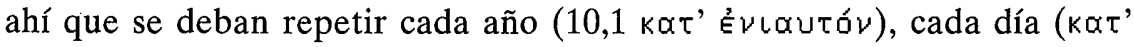

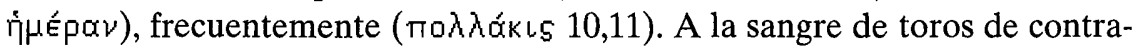

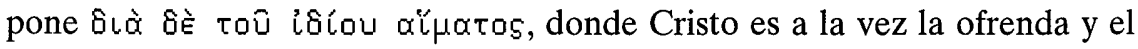
Sumo Sacerdote. "El lenguaje a través del capítulo 9 indica que la sangre de Jesús fue ofrecida en el tabernáculo celeste. Este hecho da al sacrificio de Cristo una superioridad metafísica respecto a la sangre de toros y cabras... El sacrificio de Cristo es superior porque no es material" 157.

El contraste del templo lo hallamos en 9,11 donde la tienda más grande y más perfecta es superior a la antigua tienda. Esta superioridad es expresa-

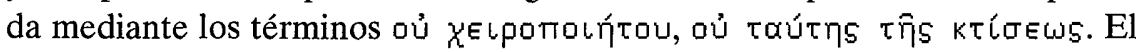
santuario terrestre, por su parte, es caracterizado como material $\chi^{\mathrm{E} \iota} \mathrm{\rho}^{-}$ пoíntos (Cfr. 9,11.23; 8,2) con un significado peyorativo, pues todo lo creado no puede traer la salvación.

Pero a pesar de todas las críticas expuestas, hay que ver un elemento positivo en la instituciones del antiguo testamento: "el autor les reconoce un valor importante, el de manifestar en concreto las exigencias de la situación y el de intentar responder a ellas. La institución sacerdotal revelaba a través de las acciones repetidas la necesidad en que se encontraban los hombres para responder plenamente a su vocación de encontrar la justa relación con Dios. Pero esta institución era impotente para satisfacer la aspiración que se expresaba por medio de ella" 158 .

El tema del culto antiguo no aparece en Heb más que en función del nuevo y verdadero sacrificio de Jesucristo ${ }^{159}$, quien realizó una transformación del hombre a través de una muerte santificante que establece una nueva relación con Dios. Es desde este punto de partida, la fe en Jesús resucitado, como se comprende que el autor de Heb haya podido formular las críticas expuestas. Por eso, pasaremos a estudiar ahora el tema central de la carta, el sacrificio de Cristo, como contraposición y culminación de los sacrificios antiguos.

\section{6.- EL SACRIFICIO DE CRISTO}

Como ya hemos visto en el capítulo anterior, nuestro autor se situa en la línea sacrificial del AT, aunque a otro nivel, por lo que presentará también a

157. Thompson, J.W., Op. Cit., p. 572.

158. Vanhoye, A., Op. Cit., p. 218.

159. Así bien dice Vanhoye, A., Op. Cit., p. 227: "El rechazo de los sacrificios rituales no es aceptable más que si uno es capaz de presentar a los hombres, como contrapartida, un acto de mediación eficaz". 
Cristo en términos sacrificiales. Hemos visto sumariamente, que este sacrificio se oponía a los efectuados en el AT, y si en el capítulo anterior calificabamos a dichos sacrificios como inoperantes, ineficaces e impotentes, por su parte el sacrificio de Cristo será el cumplimiento de todo lo que intentaban alcanzar aquéllos. Será el verdadero y único sacrificio capaz de dar al hombre la $\tau e \lambda \in i \omega \sigma \iota s$.

En cuanto que presenta la figura de Jesús dentro del ámbito sacrificial, tiene que tener presentes los elementos que formaban parte de los sacrificios rituales según la ley, es decir, una víctima, un sacerdote...

\subsection{ELEMENTOS DEL SACRIFICIO DE CRISTO}

\subsubsection{La víctima}

"Todo sumo sacerdote es tomado de entre los hombres y está puesto en favor de los hombres en todo aquello que se refiere al servicio de Dios, a fin de ofrecer dones y sacrificios por los pecados" (Heb 5,1). Pero los sacrificios que ofrecían los sacerdotes levíticos eran cosas de este mundo, como la sangre de chivos y toros $(9,12 ; 10,5)$. Es decir, se trataba únicamente de observancias exteriores, válidas transitoriamente y que no podían "transformar en su conciencia al que practica el culto" $(9,9)$. De ahí su ineficacia.

Frente a estos sacerdotes levíticos, nuestro autor nos propone la actividad sacrificial de Cristo, "porque todo sumo sacerdote está instituido para ofrecer dones y sacrificios; de ahí que necesariamente también él tuviera que ofrecer algo" (8,3). Esta nueva víctima será la ofrenda sacrificial de Cristo: "penetró en el santurario... con su propia sangre" $(9,12)$. Su ofrenda viene presentada como una oblación total de la persona oferente, que se entrega enteramente ofreciendo su propia vida y su propia sangre. Fue a la vez activo y pasivo, el que ofrecía y el que era ofrecido, el sacerdote y la víctima. Al ofrecerse a sí mismo, el sumo sacerdote de la nueva alianza ofreció el sacrificio perfecto que no necesita ser repetido.

Según lo visto en los sacrificios del AT, se exigía que la víctima fuera sin tacha o mancha. Esto se cumplía en Cristo: "Cuánto más la sangre de Cristo, que por el Espíritu Eterno se ofreció a sí mismo sin tacha a Dios, purificará de las obras muertas nuestra conciencia para rendir culto a Dios vivo" $(9,14)$. Los sacerdotes israelitas no eran dignos de ofrecerse a sí mismos, ya que eran pecadores y tenían que ofrecer sacrificios por sus propios pecados $(9,7$; $10,11)$. No eran capaces de realizar un sacrificio personal perfecto. 
Cristo, por el contrario, era una víctima digna de Dios, puesto que era sin tacha $(9,14)$. Esto se entiende en cuanto que está libre de pecado y de mal. "Como era sin tacha, Jesús no tuvo ninguna necesidad de buscar fuera de sí una víctima sacrificial, ni recurrir a la sangre de cabras ni de novillos" 160 .

El "ofrecerse a sí mismo" es un rasgo nuevo y específico que no se encontraba en el AT. La primera novedad consiste en el carácter personal de la ofrenda, dado que se sirvió de su propia sangre. Esta dimensión personal resalta mejor las relaciones de semejanza y de diferencia que hay entre la actividad sacrificial de los sumos sacerdotes israelitas y la de Jesús. Tanto por una parte como por otra, hay sacrificio y sacrificio sangriento, pero en el caso de Cristo se trata de un sacrificio personal, existencial y no de un sacrificio ritual. "En esta afirmación, el autor sintetiza dos elementos de la catequesis del NT, la presentación de Cristo como víctima sacrificial por una parte, y por otra, el aspecto de abnegación voluntaria que caracteriza a la pasión de Jesús" ${ }^{161}$. La expresión de "ofrecerse a sí mismo" es creación de nuestro autor, con la cual no quiere decir que la muerte de Cristo haya sido un suicidio.

Un elemento de la víctima sacrificial importante en muchos sacrificios era la sangre. Este término, $\alpha$ ¿ $\mu \alpha$, tiene un puesto importante en la epístola a los Heb. De 97 veces que aparece en el NT, 21 se encuentra en nuestra carta. En la sección central de Heb, la sangre viene considerada en sí misma, siguiendo así su uso dentro de la liturgia del AT. En los sacrificios rituales del culto antiguo, el uso de la sangre era de primera importancia, especialmente en el sacrificio fundamental de la alianza sinaítica y también en el sacrificio anual más solemne de todos, aquel de la gran expiación. Sin sangre sacrificial, el sumo sacerdote no podía entrar en el santuario $(9,7 ;$ Lev 16). Al igual que para establecer la primera alianza (Ex 24,3-8) ${ }^{162}$ se usó la sangre en el sacrificio, sangre de novillos y machos cabríos (9,18-21), en la segunda alianza ${ }^{163}$ también se necesitaba el derramamiento de sangre para la purificación: "según la ley, casi todas las cosas han de ser purificadas y sin efusión de sangre no hay remisión" $(9,22)$. El acontecimiento del calvario cumplió con esta exigencia, por lo que será el fundamento de la nueva alianza, siendo ésta de un orden distinto.

160. Vanhoye, A., Op. Cit., p. 207.

161. Vanhoye, A., Op. Cit., p. 207.

162. Nuestro autor estaba influido por la teología judía, según la cual se debe restablecer la alianza rota de parte de los hombres mediante el rito de la sangre, así Heb une expiación y alianza.

163. Puesto que pone la sangre de Cristo en relación con el sacrificio de la alianza, nuestro autor adopta una perspectiva que es la del relato de la última cena, en la que Jesús presentó su sangre como la sangre de la alianza (Mt 26,28; Mc 14,24; Lc 22,20; 1 Cor 11,25). 
El autor constata que esta exigencia del ritual antiguo se ha cumplido en Cristo, quien se ha servido de su propia sangre para efectuar la expiación de los pecados $(9,14-15)$ y para fundar una nueva alianza $(9,15-23)$, para entrar en el santuario y preseritarse delante de Dios $(9,12.24)$. En esto vemos una semejanza con los sacrificios antiguos, pero a la vez deja claro que existe una diferencia cualitiva entre ambos sacrificios dado que la sangre de Cristo es eficaz.

Según A.Vanhoye la "eficacia de la sangre de Cristo no se funda en la idea antigua de la eficacia expiatoria de los ritos de sangre, pues esta sangre según 10,14 'está incapacitada para borrar los pecados'...La eficacia de la sangre de Cristo, que purifica las conciencias, se debe a que Cristo 'se ofreció a sí mismo, inmolándose a Dios por medio del Espíritu Santo" ${ }^{164}$. Esta eficacia de la sangre de Cristo, Vanhoye la funda en una triple relación:

- Relación de la sangre con la ofrenda de sí mismo a Dios.

- Su relación con la integridad personal de Cristo.

- Su relación con un impulso dado por el Espíritu.

G. Mora subraya el aspecto personal y existencial de la ofrenda de Cristo durante su vida, sin el cual el derramamiento de sangre no hubiera servido: "Para Heb el elemento decisivo de la cruz de Cristo, lo que le da su valor radical, no es la sangre vertida materialmente sino la donación interior y total a la voluntad de Dios. Heb subraya en su teología que Jesús se entregó todo él, como persona, interior y libremente a Dios... No tiene una 'obsesión de sangre' propia de la mentalidad de los antiguos sacrificios; si se puede hablar así, tiene una 'obsesión de auto-oblación' existencial a Dios" ${ }^{165}$. Los sacrificios antiguos eran nulos, porque no eran el sacrificio del hombre mismo, no eran una autodonación a la voluntad de Dios (10,4-10).

Todavía Heb hace una reflexión teológica sobre la sangre en 13,20: "Dios ha hecho subir de entre los muertos al gran Pastor del rebaño en virtud de la sangre de la alianza eterna". Se ve una cierta relación entre la sangre y la resurrección. La sangre de Cristo es una sangre que resucita.

164. Vanhoye, A., Il sangue di Cristo nell'Epistola agli Ebrei, Atti della [I] Settimana. Sangue e antropologia Biblica (Roma 10-15 marzo 1980), p. 824.

165. Mora, G., Op. Cit., p.40-41. Este autor critica distintas exposiciones ambiguas de algunos autores: "Creo inadecuadas algunas exposiciones que hablan del sacrificio de Cristo como de una realidad cuasi-material que consistió en el derramamiento de la sangre de Cristo y cuyo valor radicó en la dignidad y nobleza de la víctima o en su filiación divina; y junto a este hecho habla de la entrega interior de Jesús a la voluntad de Dios como consideración piadosa de una realidad distinta y marginal... Estas visiones no saben integrar la dimensión óntico-estática, en definitva la filiación divina de Jesucristo, con la dimensión existencial-dinámica, su entrega personal al Dios vivo, en una síntesis coherente y viva" p. 41. 


\subsubsection{El sacerdote ${ }^{166}$}

Pero no basta con presentar una víctima digna de ser ofrecida a Dios (aspecto pasivo del sacrificio) sino que se requiere un sacerdote capaz de ofrecer dicha víctima, es decir, de hacer subir la víctima hasta Dios (aspecto activo del sacrificio). Cristo fue ese sacerdote capaz porque tuvo en él al Espíritu Eterno, que será quien haga subir la víctima hasta Dios.

Es mérito de Heb haber tratado el tema del sacerdocio de Cristo en profundidad. Para ello nos sirve simplemente ver las concordancias y observar dónde se aplica el vocabulario sacerdotal a Cristo o a los cristianos. Así tenemos que el término sacerdote (iepeús) aparece 7 veces en Heb de las 10 que encontramos en el NT. Del mismo modo, todas las citaciones del término sumo sacerdote (ápłlepeús) que se encuentran en el NT refiriéndose a Cristo, aparecen en Heb. No obstante, es claro que el autor no los ha inven-

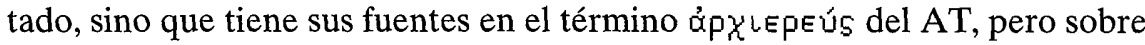
todo en la tradición evangélica, en las declaraciones de Cristo mismo. El maestro había citado el salmo 110 para expresar su cualidad mesiánica (Mc 13,36) y había asociado la noción de sacerdote a aquella de mesías. Para Spicq se debe tener encuenta el influjo de la concepción alejandrina; en "su reflexión sobre la mediación de Cristo como sacerdote soberano, Heb ha sido influenciado, puede ser por la concepción alejandrina del logos intermediario entre Dios y el mundo y su papel de intercesor" 167.

El sacerdocio antiguo estaba ligado de tal forma al culto y al santurario que si estos últimos son abolidos, el sacerdocio levítico desaparece ipso facto. Es en este principio donde encuentra su fuerza la argumentación de Heb: porque hay un sumo sacerdote instituido por Dios para ejercer un nuevo culto, es necesario que sea unido a un santuario nuevo y que desarrolle su actividad cultual.

Ya desde el principio, nuestro autor nos presenta en la exposición doctrinal 3,1-6 y 5,1-10 una relación de semejanza entre el sacerdocio de Cristo y aquél del AT. Pero será en la parte central de la obra 7,1-10,18 donde se pase de una relación de semejanza a relaciones de diferencia y de superación, poniendo de manifesto los caracteres específicos de Jesucristo. Con una relación de continuidad y semejanza hace posible que se pueda hablar de

166. Ver al respecto la gran obra monográfica de Vanhoye A., Sacerdotes antiguos, sacerdote nuevo según el nuevo testamento, p. 81-285 de la que haré áquí un resumen.

167. Spicq, C., L'Épître aux Hébreux, II, p. 128. Por su parte Rissi, M., Theologie des Hebräerbriefs. Ihre Verankerung in der Situation des Verfassers und seiner Leser, WUNT 41, Tübingen 1987, p. 59 encuentra un dualismo como influjo de "vivencias carismáticas" y "entusiasmos místicos". 
cumplimiento. Pero al mismo tiempo tenemos una ruptura radical, lo que demuestra que no se sitúan al mismo nivel. Se tiene que pasar del nivel inferior de las prefiguraciones, de los límites e imperfecciones al nivel superior de una realidad perfecta.

Mediante el salmo 110,4 el autor muestra en 5,6.10 que hay una semejanza fundamental entre Aarón y Cristo, "dado que el sacerdocio no se basa en una pretensión personal, sino en una llamada de Dios" 168. En Heb 5,9-10 escribe: "Y llegado a la perfección, se convirtió en causa de salvación eterna para todos los que le obedecen, proclamado por Dios Sumo Sacerdote a semejanza de Melquisedec". Nos presenta la eficacia y el valor salvífico de la ofrenda de Cristo que posteriormente volverá a tratar.

Pero pasemos al centro de la carta, donde cada una de las secciones tiene su tema claramente definido, aunque a la vez están íntimamente relacionados entre sí:

7,1-28 la posición personal del sacerdote

$8,1-9,28$ su actividad sacrificial

10,1-18 los frutos de esta actividad

En 7,1-3 nuestro autor intenta hacer resaltar los rasgos específicos del sacerdocio de Cristo glorificado: el sacerdocio eterno del Hijo de Dios. "Entre las tres etapas sucesivas de la revelación (Gen 14, Sal 110 y glorificación de Cristo) descubre una coherencia perfecta; sólo Cristo, Hijo de Dios, podía hacerse realmente el 'sacerdote para siempre' anunciado en el Salmo 110 y por ese mismo hecho presentarse como aquél que había sido prefigurado misteriosamente en Gen 14 con los rasgos de Melquisedec" ${ }^{169}$. Las características que nos presenta la Biblia de Melquisedec son la ausencia de genealogía humana y ausencia de límites temporales, por lo que se puede decir que tenemos una filiación divina que se manifiesta de forma negativa, haciendo de él imagen de sacerdote e hijo de Dios. De esta filiación divina $(3,5 ; 4,15 ; 5,5.8 ; 7,3.28)$ se deduce la eternidad del sacerdocio.

Haciendo patentes las diferencias y la superioridad existente del sacerdocio de Melquisedec sobre el de los sacerdotes hebreos (7,4-10), prepara así la confrontación entre el sacerdocio levítico y el de Jesucristo (7,11-19): el sacerdocio de Cristo no se basa en una pertenencia genealógica y es eterno. "El sacerdocio judío estaba regulado por la ley de 'prescripción carnal', es decir, por una ley de transmisión hereditaria, que lo vincula a la genealogía y también, por tanto, a las limitaciones de la existencia carnal. Al contrario, el

168. Vanhoye, A., Op. Cit., p. 148. Hace un amplio estudio donde expone las semejanzas de los dos sacerdocios apoyándose en paralelismos de estructura.

169. Vanhoye, A., Op. Cit., p. 164. 
nuevo sacerdocio se base en la 'fuerza de una vida indestructible', es decir en el poder de vida de la resurrección" ${ }^{170}$.

Del mismo modo, en 7, 26-28 vienen tratados los dos sacerdocios en el aspecto existencial-personal, en su relación con su propio pecado o santidad personal, respectivamente. Los contrapone: "no tiene necesidad de ofrecer cada día sacrificios primero por sus propios pecados porque ésto lo hizo de una vez para siempre ofreciéndose a sí mismo" $(7,26)$. Por su parte, éllos "tienen necesidad cada día de ofrecer sacrificios primero por sus pecados" $(7,27)$. Heb subraya así que eran "personalmente pecadores" 171 . Así nuestro autor deduce claramente que el sumo sacerdote ideal supera evidentemente a todos los sacerdotes de la ley de Moisés.

En Heb 7,11 encontramos el término técnico " $\tau \in \lambda \in$ L $\omega \sigma\llcorner\varsigma$ " que se usa para el sacrificio de consagración sacerdotal, según el cual debía llevar a cabo una transformación en el sacerdote, de modo que lo hiciera digno de entrar en contacto con Dios (Cfr. Lev 7,37; 8,22.26.8.29.31.33). Pero como ya hemos visto anteriormente, estos sacrificios resultaban inoperantes pues no transformaban interiormente al ser humano. Lo único que hacían, era simbolizar una transformación que no podían dar.

Ante esta situación era necesario que apareciera un sacerdote diferente, en quien la $\tau \in \lambda \in i \omega \sigma\llcorner\varsigma$ fuera una transformación real de su naturaleza, de modo que pudiera ofrecer un sacrificio que afectara a toda su existencia, que fuera aceptado por Dios y que renovara a la humanidad. Lo que había sido un ideal en la antigua alianza o una prescripción litúrgica se ha convertido en realidad en Cristo, quien es perfectamente santo, tanto en el orden religioso como moral (Heb 7,26) y sin necesidad de expiar sus propias faltas. La transfomación de Cristo nos la señala el autor en Heb 2,10 diciendo que se trata de una transformación profunda, realizada por Dios "mediante el sufrimiento". En Heb 5,7-9, "Cristo fue escuchado por su actitud reverente, y aun siendo Hijo, con lo que padeció experimentó la obediencia".

Será en Heb 8,1-9,28 donde el autor compare de forma amplia el misterio de la pasión y la glorificación de Cristo con el desarrollo del culto antiguo. El esquema que nos propone Vanhoye ${ }^{172}$ es el siguiente:

170. Vanhoye, A., Op. Cit., p. 173.

171. Cfr. Mora, G., Op. Cit., p. 25: "La doble situación ético-existencial de los sacerdotes (unos pecadores, otro perfecto) tiene una radical razón de ser que se expresa en 7,28: unos son 'hombres', Jesucristo es 'Hijo'. La filiación de Jesucristo, entendida como una vida totalmente en Dios, es la raíz de su santidad absoluta, de su total oblación a él. El valor del único sacerdote radica propiamente en su 'perfección' personal"

172. Vanhoye, A., Op. Cit., p. 184. 

I a) Nivel del culto
$8,3-6$
b) Cuestión de la alianza
$8,7-13$
c) Descripción del culto antiguo $9,1-10$
II c') Descripción del culto de Cristo $9,11-14$
b') Fundamentación de la alianza $\quad 9,15-23$
a') Nivel final del culto
$9,24-28$

La estructura concéntrica le permite mostrar el tema del que depende todo lo demás: la acción sacerdotal decisiva, el sacrificio. El contraste expresado entre los sacrificios antiguos (c) y el de Cristo (c') sirve para poner de relieve el valor original y definitivo del cumplimiento realizado por Cristo. Las subdivisiones (a) y (a') intentan mostrar el nivel alcanzado en la celebración del culto y se encuentran por tanto en relación directa con el tema de la situación del sacerdote respecto a Dios. En cuanto a (b) y (b'), su función es la de expresar los vínculos que existen entre el culto y la alianza.

Hacen referencia a los beneficios que comporta el sacrificio para el pueblo, tema que será tratado en Heb 10,1-18.

En Heb 9,24ss Cristo aparece como el verdadero mediador, trazando un camino que establece una relación efectiva entre el hombre y Dios. Aquí se revela como auténtico sacerdote, ya que la función del sacerdote consiste en abrir esa posibilidad de encuentro con Dios. La insistencia en la filiación divina de Cristo por parte del autor se comprende porque quiere demostrar el valor inigualable de su sacerdocio, pues constituye el vínculo más estrecho que se puede concebir entre Dios y una persona. Le asegura a Cristo una mejor posición posible para cumplir el papel de mediador.

Hablando de la estructura retórica de la sección que estudiamos, ya vimos que 10,11-14 presenta una oposición entre dos situaciones de sacerdotes, situaciones que resultan del sacrificio ofrecido y del grado de eficacia.

Se pueden resaltar algunos interrogantes que suscita el tema del sacerdocio. Así parecería que habría una contradicción entre la "no necesidad de ofrecer sacrificios" que se dedujo antes de la santidad del sacerdote (7,26-27). y por otra parte se argumenta por la existencia de un único sacrifico $(7,27)$. Es como si tuviera necesidad de ofrecer un sacrificio ${ }^{173}$. Esto se explica porque el autor quiere mantener una ofrenda privilegiada, como hace también mediante la transformación sutil del Sal 40, sustituyendo el singular por el

173. Mora, G., Op. Cit., p. 19-20 la soluciona diciendo que tanto "la santidad personal religioso-moral y el sacrificio de sí mismo, son exactamente lo mismo. Su pureza consiste precisamente en su ofrenda a Dios...Precisamente en el hecho de ofrecerse a si mismo a Dios, realizó él su santidad y su alejamiento del pecado". 
plural (10,5.8). Así ya no trata del sacrificio en sí, sino de la multiplicidad de sacrificios, por lo que deja un lugar para la ofrenda de Jesús.

¿En qué momento y mediante qué fuerza ha llegado Jesucristo a su realización y entronización como sacerdote? Se han dado varias posturas, pues para algunos es sacerdote desde toda la eternidad, como característica del verbo preexistente. Otros hablan simplemente de la consagración sacerdotal en el momento de la encarnación. Muchos la ven en su asunción y entrada en la gloria después de su muerte en la cruz. Otros dicen que como enraizada en su carácter de Hijo hecho hombre, la consagración sacerdotal de Jesús tuvo lugar en la encarnación pero no llegó a ser entronizado de manera más perfecta sino en su glorificación. Según Mora, Jesús llega a ser sacerdote en el ofrecimiento de toda su vida a Dios ${ }^{174}$. Para Vanhoye, no hay una vinculación inmediata entre filiación divina y sacerdocio, pues en varios pasajes de la carta se nos dice que Cristo "fue hecho" sumo sacerdote $(2,17 ; 5,5 ; 6,20)$, por lo que Jesucristo es sacerdote en su glorificación gracias a su pasión ${ }^{175}$.

\subsubsection{La tienda}

El término бкๆนท́ lo encontramos 20 veces en el NT con distintos significados o referido a distintas realidades. Así tenemos la tienda en su acepción ordinaria (Mt 17,4; Mc 9,5; Lc 9,33; Heb 11,9). También aparece la "tienda de David" (Hech 15,16), la "tienda de Moloc" (Hech 7,43) a la que opone la "tienda del Testimonio de Moisés" (Hech 7,44; Heb 8,5; 9,21). Se pueden entender dentro de un contexto cúltico refiriéndose al santuario, como aparece con el concepto de "la primera tienda" (Heb 9,2.3.6.8) o "los que dan culto en la tienda" (Heb 13,10), que se refiere a la parte interior del santuario mosaico. Si habla de una "primera tienda", es que nuestro autor quiere hacer referencia a una segunda "tienda mayor y más perfecta" $(9,11)$ o a la "tienda verdadera" $(8,2)$. Lc 17,9, por su parte, usa la expresión "en las eternas moradas".

Si nos centramos en el cap 9, vemos que entre 9,1-10 y 9,11-12 se establece un contraste en cuanto a la tienda: la primera tienda y los ritos antiguos

174. Mora, G., Op. Cit., p. 32 : "Jesús llegó a ser sumo sacerdote en y por su entrada ante Dios; pero es preciso entender esta entrada, no como algo más allá de su sacrificio, sino como algo idéntico a él. Jesús llegó a ser sumo sacerdote en su ofrecimiento a Dios de toda su vida, en su sacrificio, y precisamente por ello. Su 'consagración' por arte de Dios -dimensión pasiva- se identifica con su propia entrega a El -dimensión activa-".

175. Vanhoye, A., Op. Cit., p. 168: "El sacerdote al que prefigura Melquisedec no es el hijo de Dios en su preexistencia, ni Jesús en su vida terrena, sino Cristo, el Hijo de Dios, glorificado como consecuencia de su pasión". 
no donan el acceso a Dios, mientras que la tienda nueva y la sangre de Cristo permiten la entrada definitiva en el santuario. En 9,11 la tienda será "más grande y más perfecta", lo que indica que la primera era limitada y deficiente, "no hecha por manos de hombres, es decir, no de este mundo" indicando que la primera había sido hecha por manos de los israelitas $(9,2 ; 8,5)$ y por tanto de este mundo.

El autor piensa en esta tienda verdadera ya en 8,2 "tenemos un sumo Sacerdote que se sentó ... al servicio del santuario y de la tienda verdadera, erigida por el Señor no por un hombre", distinguiendo entre el santuario y la tienda, esta última como medio de acceso. Pero será 9,11 donde nos aclare el término.

¿Cómo se ha de entender el término okquŕ de 9,11, en sentido concreto o metafórico? El P.Vanhoye ${ }^{176}$ nos hace un estudio específico de este versículo difícil por las distintas interpretaciones que se han dado. En primer lugar, tenemos la explicación que entiende la tienda como una imaginación mitológica de un templo celeste concebido materialmente a imagen del templo terrestre y divido en dos partes. Pero esta postura no encuentra apoyo en el texto y no está en la línea de pensamiento de nuestro autor.

La interpretación cosmológica considera la tienda como un espacio: así como el sumo sacerdote atravesó la primera tienda para llegar al Santo de los Santos, también Cristo atravesó un espacio, llamado metafóricamente tienda para presentarse delante de Dios. Las objecciones que plantea Vanhoye son debidas al paralelismo existente entre la sangre de Cristo y la tienda. No siendo la tienda de esta creación $(9,11)$, ésta no se puede identificar con los cielos intermedios, los cuales forman parte de lo creado. "Diciendo que la nueva tienda no es de esta creación, el autor excluye no solamente una interpretación terrestre, sino toda interpretación cosmológica" ${ }^{177}$.

Otras interpretaciones merecen nuestra atención pues se apoyan en la carta y en la catequesis primitiva. Sin embargo, son incompletas o confusas. Según G. Mora, “ $₫ k \eta \nu \eta ́$ se refiere con toda probabilidad al cuerpo de Cristo en el sentido más amplio de su humanidad. Inclinan a esta lectura, en primer lugar, el binomio intentado por el paralelismo interno de 9,11-12: tienda (cuerpo)-sangre; además del paralelismo de nuestro pasaje con 10,19-21 (binomio sangre-carne); también la importancia soteriológica que el texto atribuye al tabernáculo" ${ }^{178}$. Pero decir que la tienda es el cuerpo de Cristo no es suficiente, pues del cuerpo de Jesús no se puede afirmar que no sea de

176. Vanhoye, A., "Par la tente plus grande e plus perfaite" (Heb 9,11), Bib 46 (1965) p. 128. Aquí expondré su tesis y sus argumentos.

177. Vanhoye, A., Op. Cit., p. 8.

178. Mora, G., Op. Cit., p. 28. 
esta creación. Tampoco conviene identificar la tienda con la iglesia, pues esto implicaría que Cristo depende de la iglesia para llegar a Dios.

Por su parte Vanhoye propone la teoría que se refiere al cuerpo resucitado de Cristo: "Si se precisa que la tienda designa el cuerpo resucitado, entendido en toda su profundidad y toda la extensión de su misterio, entonces desaparecen las objeciones y todo se aclara. Cada uno de los elementos del texto recibe su valor; la estructura del desarrollo se explica sin dificultad; las otras afirmaciones de la epístola pueden ser integradas y los distintos aspectos de la tradición bíblica y de la catequesis primitiva referente al tema del templo... lejos de excluirse se insertan cada uno en su lugar dentro de un conjunto armonioso" 179 .

Así la tienda verdadera es el templo reconstruido en tres días (Mc 14,58; 15,29), no hecho de manos humanas, ni de esta creación y está en paralelo con la sangre $(9,12)$. Ésta interpretación está apoyada por 10,19-20.

Esta teoría también ha sido criticada ${ }^{180}$ aunque hasta ahora queda como la más aceptable. Por su parte J. Swetnam, partiendo de los estudios de A.Vanhoye y A. Adam ${ }^{181}$ y estudiando los pasajes de 9,11-12; 8,2 y 10,19-20, concluye que la "tienda" de 9,11 se entiende como la Eucaristía, cuerpo glo-

179. Vanhoye, A., Op. Cit., p. 28. Esta misma idea la desarrolla en su libro Sacerdotes antiguos, sacerdote nuevo según el nuevo Testamento, p. 198-205, donde además de lo dicho anteriormente, presenta este evento de la resurrección como una nueva creación para el hombre, p. 204: "La resurrección se presenta como una renovación completa de lo humano en Cristo, renovación tan profunda que es preciso hablar de nueva creación y de hombre nuevo. Su resultado consiste ante todo en hacer a la humanidad capaz de una comunicación perfecta con Dios".

180. Así Loader, R.G.W., Sohn und Hoherpriester. Eine Traditionsgeschichtliche Untersuchung zur Christologie des Hebräerbriefes, WMANT 53, Neukirchen-Vluyn 1981, para quien "la tienda" significaría el santurario celeste: "Mediante las palabras del verso $(9,11)$ es claro que aquí se piensa en primer lugar en la antítesis entre el templo celeste y el terrestre... La frase no significa que habría ido de una tienda a otra, sino que Cristo fue a través del santuario celeste cuando entró en el santo de los santos" p. 166-167. Este autor declara que no son convincentes los argumentos que presentan 9,11 significando alegóricamente a Cristo o a la Iglesia. "No es legítimo atribuir aquí imaginariamente interpretaciones de otros lugares del NT, como el templo visto como cuerpo de Cristo en Jn 2,19 (Cfr. Mc 14,58) (Vanhoye, Swetnam). El problema que se crea con el texto habla por sí mismo contra tal especulación. Tales tentativas de ver el cuerpo terrestre de Jesús como celeste... son acríticas, así como las tentativas de entender el cuerpo como el cuerpo resucitado (Vanhoye, Smith), o el cuerpo de la Iglesia (Ungeheuer, Westcott), o el cuerpo eucarístico (Swetnam). Para tal empleo de la presentación del santuario no se puede tampoco apelar a una presunta regla, que "óá" tiene que tener el mismo significa-

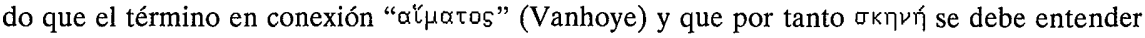

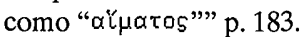

181. Adam, A., Ein vergessener Aspekt des frühchristlichen Herrenmahles. Eine Beitrag zur Geschichte des Abendmahlsverständnisses der Alter Kirche, Theologische Literaturzeitung 88 (1963) p. 9-20. 
rificado de Cristo ${ }^{182}$. Aporta cinco argumentos ${ }^{183}$ para defender su postura. Creo que su propuesta se basa en una identificación de la "sangre" de 9,12 con la "sangre eucarística" de los relatos de la pasión, por lo que la tienda, siendo el otro elemento unido a la sangre para entrar en el santuario, tendría que corresponder al cuerpo eucarístico.

\subsection{CRISTO, UNICO Y SOLO SACRIFICIO}

El autor subraya el aspecto decisivo y definitivo del sacrificio de Cristo. Como Cristo llegó y completó el sacrifico prefigurado desde antiguo, siendo este perfecto y teniendo una eficacia total y real, no tiene porque repetirlo, como hacían hasta entonces los sumos sacerdotes, que renovaban cada año su empeño $(9,25 ; 10,1)$. Frente a la repetición continua de los sacrificios del AT, nuestro autor opone el verdadero y único sacrificio de Cristo. No es un sistema repetitivo y cíclico, pues con este verdadero sacrificio se obtiene la abolición de los pecados, abriendo para los hombres perspectivas de salvación: "Para ello habría tenido que sufrir muchas veces desde la creación del mundo. Sino que se ha manifestado ahora una sola vez, en la plenitud de los tiempos, para la destrucción del pecado mediante su sacrificio" $(9,26)$.

$\mathrm{El}$ autor pone especial énfasis en la unicidad de la ofrenda de Cristo y que es imposible repetirla. La terminología que usa refiriéndose al sacrificio de Cristo no deja dudas. Así usa 4 veces el término ỡ $\pi \alpha \xi(9,7.26 .28 ; 10,2)$ y 3 veces É фর́ $\Pi \alpha \xi(7,27 ; 9,12 ; 10,10)$. Esto es subrayado con el uso del numeral

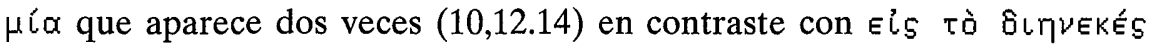
$(10,1)$ y по $\lambda \lambda$ ók เ $(10,11)$ del sacerdocio de Aarón.

Pero no simplemente el uso de la terminología indica la unicidad de dicho sacrificio, sino que ésto viene reforzado mucho más mediante el uso cuidadoso de los tiempos griegos ${ }^{184}$. Así "refiriéndose a la acción del sumo sacerdote de la casa de Aarón usa invariablemente el tiempo presente $(5,1.3$; $8,3 a .4 ; 9,7 ; 10,1.2 .8$, nunca de la ofrenda de Cristo) lo que muestra su carácter

182. Swetnam, J., "The Greater and more Perfect Tend". A contribution to the Discussion of Hebrews 9,11, Bib 47 (1966) p. 91-106.

183. Cfr. Swetnam, J., Op. Cit., p. 104, su argumentación se base principalmente en el primer argumento que da: "La forma en que el autor de Heb ha puesto en paralelo la tienda con la sangre (eucarística) de Cristo $(9,11-12 ; 10,19-20 ; 10,29)$ ". Para apoyar su tesis dice "que no es posible diferenciar o delimitar claramente entre el cuerpo resucitado de Cristo y el cuerpo eucarístico de Cristo" p. 105.

184. Para ver la diferencia de los aspectos verbales griegos (aoristo, presente o imperfecto), se puede consultar Zerwick, M., Biblical Greek, Rome 1963, nº 241.242.247.270. 
continuo. Por el contrario, cuando habla de la ofrenda de Cristo, usa invariablemente el aoristo $(8,3 \mathrm{~b} ; 9,14 ; 10,12)$ " ${ }^{185}$. El contraste más claro lo encontramos en 8,3: "Porque todo sumo sacerdote está instituido para ofrecer (

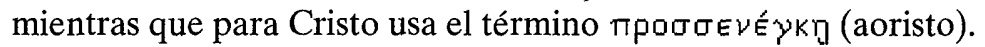

Para nuestro autor, el sacrificio de Cristo fue hecho una sola vez en la cruz y lo categoriza como único y simple, pues su efecto, dado que obtenía la $T E \lambda E \zeta \omega \sigma\llcorner 5$, ha suplantado y erradicado el pecado, motivo por el que se ofrecían sacrificios en la antigua alianza. En Cristo, un único sacrificio vale al mismo tiempo para el sacerdote y para todo el pueblo. En un mismo y único acto de ofrenda, Cristo recibe la consagración sacerdotal y asocia estrechamente a élla a todos los fieles.

En este sacrificicio hay que entender dos aspectos indisociables, la pasión y la glorificación. Este acto superó infinitamente a los sacrificios antiguos, por lo que éstos ya no pueden considerarse como válidos, dado que son ineficaces, siendo formas vacías, simples prefiguraciones del verdadero sacrificio, y por dicho motivo las instituciones antiguas serán sustituidas por una nueva realidad que cumpla mejor sus funciones.

\subsection{LA EFICACIA DEL SACRIFICIO DE CRISTO}

La cuestión clave sobre el sacrificio de Cristo será el sentido y el alcance de este eficacia. ¿Concibe Heb el sacrificio de Cristo únicamente en función de la purificación de los hombres pecadores o ve también en él algo fundamental respecto a Cristo mismo? ¿La sangre derramada está en función salvadora de su sacerdocio o concibe la perfección sacerdotal de Jesús como algo fundamentalmente personal? La cuestión de la eficacia del sacrificio en favor de los hombres aparece claramente en nuestra sección 10,1-18. No obstante, antes ya anticipa las ideas que después desarrollará en dicha sección. Así en 9,11-12 afirma la eficacia del sacrificio: Cristo consiguió una redención eterna, entrando en el santuario mediante su sangre. En la frase 9,13-14 se esfuerza por tener encuenta esta eficacia y señalar concretamente su alcance: la dimensión espiritual de la ofrenda de Cristo asegura a su sangre el poder de actuar en lo más profundo del hombre, purificando las conciencias, y de establecer así una comunicación auténtica con Dios. Según G.Mora las dos frases constituyen dos perspectivas distintas del único sacrificio de

185. Stott, W., The conception of 'Offering' in the Epistle to the Hebrews, NTS 9 (1962-63) p. 65 . 
Cristo. En ambas el sujeto es Cristo, pero en la primera el movimiento del verbo termina en $\mathrm{El} \mathrm{mismo} \mathrm{(entró),} \mathrm{mientras} \mathrm{que} \mathrm{en} \mathrm{la} \mathrm{segunda} \mathrm{pasa} \mathrm{a} \mathrm{los}$ que están fuera de El (purificará). Por tanto tenemos una dimensión personal y salvífica. Según este exégeta, "el análisis gramatical inclina a considerar como central lo que he llamado la dimensión personal (entró es el verbo principal), viniendo a su luz la dimensión salvífica (encontrar la redención, es frase secundaria coordinada)" ${ }^{186}$.

Pero debemos afirmar que la muerte de Jesús es un acto solidario en favor de los hombres. Como sumo sacerdote, con su muerte entró en el santuario verdadero, pero ese acontecimiento no puede reducirse a una eficacia personal pues entonces ya no sería sacerdotal, sino que extiende sus consecuencias decisivas a la existencia de todos los hombres. Esto lo explica el autor en nuestra sección (10,1-18)

Conocedor de la dialéctica de contrastes como ya hemos visto, nuestro autor en 10,1-18 contrapone a la ineficacia de los sacrificios antiguos la perfecta eficacia de la ofrenda de Cristo. Para ello se sirve de textos escriturarios como son el Sal $40(10,5-9)$, Sal $110(10,12-13)$ y las palabras de Jeremías $(10,16-17)$. Es ante la impotencia de los sacrificios del AT, vista en el capítulo anterior, que hace necesaria la venida de Cristo y su único sacrificio eficaz: “¡He aquí que vengo!” (10,5-7). "La eficacia del sacrificio de Cristo la encontramos en dos frases que utilizan el perfecto griego ${ }^{187}$, el cual expresa el resultado duradero de una acción pasada: 'Hemos sido santificados, merced a la oblación de una vez para siempre del cuerpo de Cristo' $(10,10)$; 'mediante una sola oblación ha llevado a la perfección para siempre a los santificados' $(10,14)$ " ${ }^{188}$.

¿Qué efectos tiene el acto sacrificial de Cristo? El resultado es la transformación del hombre para poder acercarse y entrar en contacto con Dios, "pues dan la perfección a los que se acercan" $(10,1)$. Era lo que pretendían los sacrificios antiguos. Pero éstos al ser totalmente exteriores, no afectaban para nada al hombre, siendo rechazos por Dios (10,7-9; Cfr. Sal 40). Frente a la exterioridad de dichos sacrificio tenemos una nueva ofrenda personal de

186. Mora, G., Op. Cit., p. 27. Esta sección la define "la eficacia del sacrificio de Cristo en El mismo". Afirmando el aspecto personal de la eficacia de la ofrenda, dice que Vanhoye "limita excesivamente, desenfocando su real perspectiva, al entender aquella salvación exclusivamente como obra más allá de Jesucristo: la santificación de la Iglesia" p. 29.

187. Una forma más complicada de explicar el perfecto nos la presenta Zerwick, M., Op. Cit., $\mathrm{n}^{\circ}$ 285: "En esencia...el tiempo perfecto griego corresponde a uno inglés, el cual no es un tiempo pasado, sino uno presente, indicando no una acción pasada como tal, sino el resultado presente de 'estado de hechos' de una acción pasada".

188. Vanhoye, A., Op. Cit., p. 222. 
Cristo, la cual Dios no puede rechazar y tiene incidencia en la conciencia de pecado de los que ofrecen ese culto $(10,2)$, por lo que les librará de dichos pecados haciendo que no se renueve su recuerdo o memoria $(10,3)$.

Otro indicio de la eficacia es el aspecto ya visto de la unicidad del sacrificio de Cristo: alcanzado su objetivo, no necesita repetirlo, pues "ha llevado a la perfección para siempre a los santificados" $(10,14)$. Hay que subrayar el adverbio 'siempre' indicando en sí mismo la perfección del sacrificio.

Esta eficacia viene corroborada mediante la profesión de Jeremías que la coloca en los labios del Espíritu Santo: "Y de sus pecados e iniquidades ya no me acordaré" $(10,17)$. La conclusión a la que llega el autor, después de haber expuestos sus argumentos es clara: ante la eficacia del sacrificio de Cristo, los hombres ya no necesitan la repetición de sacrificios pues "donde hay remisión de estas cosas ya no hay remisión por el pecado" $(10,18)$. El hombre por medio de Cristo ha vencido el pecado, por lo que ha quedado transformado.

El hacer la voluntad del Padre por parte de Cristo, obtiene, por una parte, que Cristo se siente a la diestra de Dios para siempre $(10,12)$ y por otra, obtiene para los hombres el perdón, la santificación $(10,10.14)$ y la perfección $(10,14)$. Cristo, como sujeto, conunica dicha perfección. El estar a la diestra de Dios y el comunicar la perfección nos muestra que el hombre no está al mismo nivel que Jesucristo. En el hombre la transformación llevada a cabo mediante el sacrifico de Cristo es quitarle el pecado, mientras que en Cristo no le quita los pecados, dado que ya era puro y sin tacha desde el inicio.

El único y verdadero sacrificio vale al mismo tiempo para el sacerdote y para todo el pueblo.

La eficacia del sacrificio de Cristo tiene unas repercusiones para la vida del cristiano como nos describe 10,19-25, donde se señala una fuerte conexión entre la situación religiosa creada por Cristo (los tres primeros versículo) y la invitación a adoptar las actitudes correspondientes (los 4 últimos versículos).

La eficacia para los cristianos está en la novedad de las relaciones entre los cristianos y Dios, pues han quedado suprimidas las barreras que los separaban, "teniendo pues, hermanos, plena seguridad para entrar en el santuario", mientras que este hecho se limitaba anteriormente al sumo sacerdote, quien podía entrar solamente una vez al año.

La ofrenda de Cristo hace que los cristianos se conviertan en sacerdotes, por lo que tienen el privilegio de presentar a Dios ofrendas en sacrificio. Estas ofrendas serán evidentemente distintas de aquellas ofrecidas en el ritual del antiguo culto, pues deben transformar la propia existencia por medio de la caridad divina. El culto cristiano tiene que modelarse según el 
sacrificio de Cristo, es decir, conlleva la adhesión y entrega personal a Dios y la donación a los demás seres humanos $(13,16)$.

Es la humanidad glorificada de Cristo la que nos abre el camino nuevo y vivo para entrar en el santuario, quien será el guía en este camino hacia Dios y al final nos presentará ante Dios, dado que es "un gran sacerdote".

Pero para que los efectos de la ofrenda de Cristo sean eficaces, en el cristiano se necesitan unas actitudes que vienen descritas en 10,22-25, consistiendo en la adhesión, en plenitud de fe, a Cristo sacerdote. Frente a la ley $(10,1)$ opone la fe fundamentada en la eficacia del sacrificio de Cristo, que introduce a los hombres en comunión con Cristo. Otra virtud es la esperanza de alcanzar esta meta, dado que Cristo, pionero, también la ha alcanzado. La tercera es la caridad manifestada en la ayuda mutua y en las buenas obras.

Unidas a las actitudes espirituales, el autor evoca los medios concretos para unirse a la mediación de Cristo por medio de los sacramentos. Tenemos una alusión al bautismo $(10,22)$, a la eucaristía $(10,19-20)$ pues la frase corresponde a la realidad de una celebración eucarística ${ }^{189}$. Esta interpretación eucarística viene apoyada por Heb 13,10: "Tenemos un altar del cual no tienen derecho a comer los que dan culto en la tienda". Es un pasaje que evoca la eucaristía y el culto sacrificial cristiano ${ }^{190}$.

El cuerpo de Cristo y su sangre están disponibles actualmente porque se hacen presentes en la existencia de los cristianos de una forma sacramental.

\section{CONCLUSION}

La epístola nos insinúa que algunos cristianos participaban en los ritos del AT y en el altar $(13,10)^{191}$, lo cual indicaría que algunos de dicha comunidad añoraban los sacrificios veterotestamentarios. Ante esto, el autor intenta responder a la pregunta: ¿Es la comunidad cristiana una comunidad sin

189. Tal vez fuera este el Sitz im Leben originario de nuestra carta-sermón.

190. Sin embargo, no todos los exégetas interpretan este texto en un ambiente eucarístico. Para ello basta ver la bibliografía que nos presenta Vanhoye, A., Op. Cit., p. 239, nota 47. Loader, R.G.W., Op. Cit., p. 179, comentando este versículo, y en concreto el altar, nos dice que "si no se quiere totalmente espiritualizar, entonces se entendería con él seguramente la celebración eucarística. Ello no significa que el altar se refiera a la mesa de la eucarístia, sino solamente que nosotros tenemos nuestro propio culto en un nivel espiritual, en el cual nosotros comemos en la celebración litúrgica y celebramos el significado de la cruz".

191. Este problema ya había surguido en la comunidad de Corintio, pues allí se trataba de inmolaciones a los ídolos (1 Cor 8-10). San Pablo ve la incompatilidad entre los sacrificios y la participación a la eucaristía, "no podéis participar de la mesa del Señor y de la mesa de los demonios" (1 Cor 10,21). 
sacrificios? El escritor quiere dejar bien claro que los cristianos tienen un auténtico sacrificio, que es aquél de la muerte de Cristo. Para él, la nueva liturgia no consiste en ceremonias sino en un hecho real, la muerte de Cristo, ofrenda que transforma al ser humano y le hace digno de entrar en la presencia de Dios. Así los cristianos tienen que superar la concepción antigua de culto y adaptarse a la nueva situación creada por la nueva liturgia cristiana, donde la sangre de las víctimas no corre.

Para convencer a sus oyentes, el autor nos expone en primer lugar el funcionamiento de la institución sacrificial del AT y su finalidad. Estos vienen tratados ampliamente en el cap. 9, siendo la síntesis central de la obra. Nuestra sección continúa con esta temática tomando la imagen del día de la expiación (10,1-3) para la interpretación sacrificial de la muerte de Cristo. Para ello contrapone a los sacrificios de los animales la ofrenda personal de Cristo que sustituirá todo el sistema ritual precedente. Se servirá en 10,4-10 de una utilización habilísima de los textos de la Escritura para la confrontación de los dos cultos y mostrar así que la multiplicidad de sacrificios ya era rechazada por las Escrituras. Ante esto, propone su sustitución por la dedicación de Cristo de hacer la voluntad del Padre, que era el verdadero sacrificio que proponían los textos bíblicos.

Para confirmar y subrayar el rechazo de esos sacrificios, opone dos situaciones de sacerdotes, el sacerdocio levítico y el de Cristo (10,11-14). Frente a los sacerdotes que ofrecen siempre los mismos sacrificios sin obtener el perdón de los pecados, antepone la única ofrenda personal y existencial del nuevo sacerdote, que entregándose a sí mismo, ha llevado a la perfección a los que él santifica. Para finalizar, el autor confirma su tesis con la citación de Jeremías, por lo que el Señor no se acordará de los pecados. Cristo, así, ha alcanzado el objetivo que se proponían los sacrificios antiguos, y las prefiguraciones, por tanto, han de ser sustituidas por el sacrificio real. Esta crítica hace imposible considerar las realidades de la nueva Alianza como una mera continuación de la antigua economía y del antiguo aparato sacrificial.

Mediante este razonamiento lógico, afirma que la ofrenda de Cristo es el único y verdadero sacrificio, excluyendo todo otro tipo, pues los antiguos ritos no constituían verdaderos sacrificios, eran simples tentativas impotentes, pues, dado que eran ritos exteriores, no podían alcanzar a la conciencia del hombre para transformarlo. No eran agradables a Dios, porque las víctimas eran impuras y los sacerdotes eran hombres pecadores que intentaban ser una figuración del verdadero sacerdote. Por el contrario, en la muerte de Cristo se encuentran realizadas de forma perfecta todas las condiciones de un sacrificio auténtico. 
Habiendo reelaborado la noción de sacrificio, nuestro autor ha hecho posible la interpretación sacerdotal de numerosas afirmaciones de la fe en Cristo, que no eran sacrificiales en el sentido antiguo del término. La nueva noción de sacrificio ofrece un fundamento sólido y seguro a la concepción sacrificial de la existencia cristiana $(13,15-16)$.

¿Cómo ha presentado el autor la muerte de Cristo? La presenta bajo distintos aspectos. En primer lugar, mediante la antítesis del sistema ritual antiguo y refiriéndose a la fiesta del Yom Kippur, Cristo viene presentado como una víctima expiatoria que obtiene el perdón de los pecados y la perfección para siempre de los santificados $(9,28 ; 10,12-14)$, por lo que anulará los sacrificios expiatorios, dado que "donde hay remisión de estas cosas, ya no hay más obligación por el pecado" $(10,18)$.

También viene presentada como un sacrificio de Alianza, pues Cristo sella con su sangre la nueva Alianza, siendo su mediador (8,6-7). " $\mathrm{Al}$ decir nueva, declaró anticuada la primera, y lo anticuado y viejo está a punto de cesar" $(8,13)$. Algunos textos bíblicos preparaban esta sorprendente fusión, ya que unían alianza y expiación.

Su muerte es también condición para entrar en el Nuevo Testamento, "pues donde hay testamento, se requiere la muerte del testador" $(9,16)$.

D. Alvarez Cineira, osa

Estudio Teológico Agustiniano

Valladolid 